\title{
Automatic load-distributing band CPR
}

\section{(AutoPulse ${ }^{\mathrm{TM}}$ ) in prone position: A feasibility study in a mechanical model}

\section{Urs Pietsch ( $\square$ urs.pietsch@kssg.ch )}

Department of Anaesthesiology and Intensive Care Medicine,1 Cantonal Hospital St. Gallen, St. Gallen, Switzerland

Jürgen Knapp

Department of Anaesthesiology and Pain Medicine,3 Inselspital, Bern University Hospital, University of Bern, Bern, Switzerland

\section{Volker Wenzel}

Department of Anaesthesiology and Intensive Care Medicine 3 Friedrichshafen Regional Hospital

\section{Volker Lischke}

Emergency Medical Service

\section{Roland Albrecht}

Swiss Air-Ambulance,5 Rega (Rettungsflugwacht / Guarde Aérienne), Zurich, Switzerland

\section{Short Report}

Keywords: SARS-CoV-2 , CPR, Prone CPR

Posted Date: August 5th, 2020

DOl: https://doi.org/10.21203/rs.3.rs-53065/v1

License: (a) (i) This work is licensed under a Creative Commons Attribution 4.0 International License.

Read Full License

Version of Record: A version of this preprint was published at Der Anaesthesist on August 5th, 2020. See the published version at https://doi.org/10.1007/s00101-020-00851-1. 


\section{Abstract}

Background: Due to SARS-CoV-2 respiratory failure, prone positioning of patients with respiratory and hemodynamic instability has become a frequent intervention in intensive care units (ICUs), and even in patients undergoing transfer in an ambulance or helicopter. The question becomes how to perform safe and effective CPR in prone position, achieving both an optimal outcome for the patient and optimal protection of staff from infection.

Materials and Methods: We conducted a feasibility study to assess the effects of CPR with an automatic load-distributing band (AutoPulse ${ }^{\mathrm{TM}}$ ) in prone position.

Results: In supine position, AutoPulse ${ }^{\mathrm{TM}}$ generated a constant pressure depth of $3 \mathrm{~cm}$ at a frequency of $84 / \mathrm{min}$. In prone position, AutoPulse ${ }^{\mathrm{TM}}$ generated a constant pressure depth of $2.6 \mathrm{~cm}$ at a frequency of $84 / \mathrm{min}$.

Conclusion: We found that AutoPulse ${ }^{\mathrm{TM}} \mathrm{CPR}$ was feasible in manikins in both prone and supine positions.

\section{Full Text}

Due to SARS-CoV-2 respiratory failure, prone positioning of patients with respiratory and hemodynamic instability has become a frequent intervention in intensive care units (ICUs), and even in patients undergoing transfer in an ambulance or helicopter (1). The question becomes how to perform safe and effective CPR in prone position, achieving both an optimal outcome for the patient and optimal protection of staff from infection. An increasing number of case reports and recommendations addressing manual CPR for SARS-CoV-2 patients in prone position were published recently $(1,2)$. As in every CPR attempt, the goal is immediate onset of high-quality chest compressions with minimal hands-off time. Initiating CPR in prone position may be the best way to treat an intubated SARS-CoV-2 ICU patient without a significant delay caused by the complex, critical and time-consuming process of maneuvering from prone into supine position. The AutoPulse ${ }^{\mathrm{TM}}$ (ZOLL Circulation, San José, CA, USA), a mechanical chest compression device, can be easily and rapidly positioned under the patient, with the band close to the patient's back at the level of the shoulder blades (Figure1, Panel C). This provides optimal chest compressions with a constant $20 \%$ reduction in the anterior-posterior dimension.

We conducted a feasibility study to assess the effects of CPR with an automatic load-distributing band (AutoPulse ${ }^{\mathrm{TM}}$ ) in prone position. CPR in supine position was compared to CPR in prone position in a CPR manikin model (Ambu ${ }^{\odot}$ Man Airway manikin) resuscitated with an Autopulse ${ }^{\mathrm{TM}}$. Chest compressions were recorded and analyzed with an AmbuMan Management Tool. In supine position, AutoPulse ${ }^{\mathrm{TM}}$ generated a constant pressure depth of $3 \mathrm{~cm}$ at a frequency of $84 / \mathrm{min}$. In prone position, AutoPulse $\mathrm{TM}^{\mathrm{TM}}$ generated a constant pressure depth of $2.6 \mathrm{~cm}$ at a frequency of $84 / \mathrm{min}$ (Figure 1 ). 
As a limitation, this is a manikin model and resuscitation manikins were not constructed to receive compressions via the back, which may explain the slightly less compression depth in this study.

We found that AutoPulse ${ }^{T M}$ CPR was feasible in manikins in both prone and supine positions. Our observations now need to be confirmed clinically.

\section{Declarations}

\section{Ethics Approval}

The regional committees for medical and health research ethics of St. Gallen, Switzerland (EKOS), classified this study as a project not requiring ethical approval.

\section{Consent for publication}

Not applicable

\section{Availability of data and supporting materials section}

Not applicable

\section{Funding}

None

\section{Competing interest}

The authors declare that they have no competing interest.

\section{Author contributions}

Urs Pietsch: conceptualization, investigation, and writing of original draft

Volker Wenzel: conceptualization, review \& editing

Jürgen Knapp, Volker Lischke: supervision, review, and editing.

Roland Albrecht: conceptualization, supervision, review and editing

\section{Acknowledgements}

We would like to thank Jeannie Wurz, Bern, for editorial assistance.

\section{Conflict of interest statement}

The authors declare no conflicts of interest. 


\section{Abbreviations}

CPR Cardiopulmonary resuscitation

\section{References}

1. Edelson DP, Sasson C, Chan PS, Atkins DL, Aziz K, Becker LB, et al. Interim Guidance for Basic and Advanced Life Support in Adults, Children, and Neonates With Suspected or Confirmed COVID-19: From the Emergency Cardiovascular Care Committee and Get With The Guidelines-Resuscitation Adult and Pediatric Task Forces of the American Heart Association. Circulation. 2020;141(25):e933e43.

2. Barker J, Koeckerling D, West R. A need for prone position CPR guidance for intubated and nonintubated patients during the COVID-19 pandemic. Resuscitation. 2020;151:135-6.

\section{Figures}

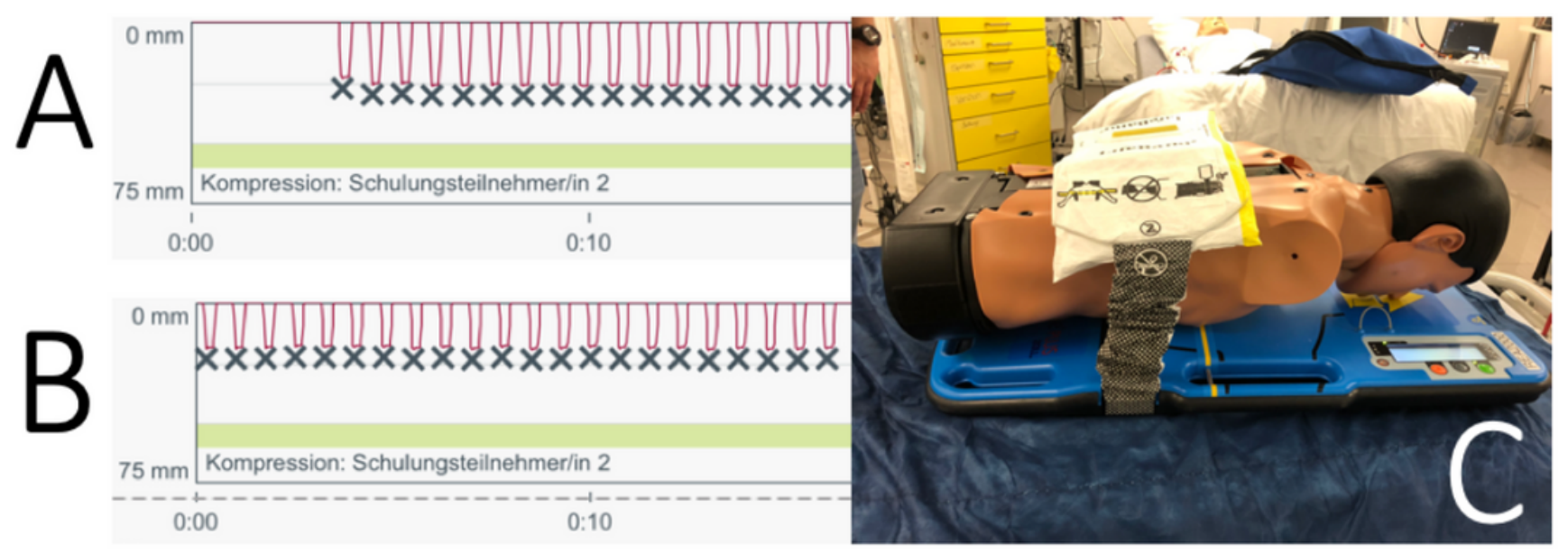

Figure 1

A. chest compression in supine position B. chest compression in prone position C. Manikin Ambu Man Airway 